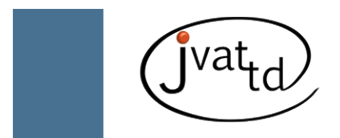

\title{
Acutolysin C, a weak hemorrhagic toxin from the venom of Agkistrodon acutus with leucoagglutination activity
}

Wei CB (1, 2), Chen J (3), Li JH (4)

(1) Department of Chemistry and Biology, Western Anhui University, Lu'an, Anhui Province, People's Republic of China; (2) Lu'an Bionical Sensor and Testing Technique Laboratory of Anhui Province, Lu'an, Anhui Province, People's Republic of China; (3) Faculty of Life Science and Biotechnology, Ningbo University, Ningbo, Zhejiang Province, People's Republic of China; (4) Life Science College, Anhui University, Hefei, Anhui Province, People's Republic of China.

\begin{abstract}
The properties and agglutination activity of acutolysin C, a hemorrhagic metalloproteinase obtained from Agkistrodon acutus venom, were studied herein. Acutolysin C is a basic glycoprotein consisting of a single polypeptide chain with a molecular weight of $23.1 \mathrm{kDa}$ and $\mathrm{pl} 8.7$, containing one $\mathrm{Zn}^{2+}$ and one $\mathrm{Ca}^{2}+$ per molecule. It possesses caseinolytic, weak lethal $\left(\mathrm{LD}_{50}=7.6 \mathrm{mg} / \mathrm{kg}\right)$ and weak hemorrhagic $(\mathrm{MHD}=$ $12.0 \mu \mathrm{g}$ ) activities, but does not present fibrinolytic, fibrinogenolytic, arginine esterase and phospholipase $\mathrm{A}_{2}$ actions. In addition, it revealed agglutination activity on some animal lymphocytes, including five species of mammals, six of birds, three of reptiles and one of amphibians, but had no effect on lymphocytes from two species of reptiles, one amphibian and nine species of fish. It had no effects on the erythrocytes and platelets of all 26 animal species tested. Both leucoagglutination and caseinolytic activities were inhibited by EDTA; while cysteine, 2-mercaptoethanol, 1,4-dithiothreitol, glutathione, serum against acutolysin C and serum against homologous snake venom as well as glucose, sucrose, mannose, lactose and galactose had no effects on inhibition. The lowest concentration of acutolysin $C$ that induced mouse lymphocyte agglutination was $2.5 \mu \mathrm{g} / \mathrm{mL}$. Acutolysin $C$ is an interesting substance since it is the first member of the hemorrhagin family to be shown to have leucoagglutination activity.
\end{abstract}

Key words: Agkistrodon acutus, acutolysin C, hemorrhagin, leucoagglutination activity.

\section{INTRODUCTION}

Hamorrhagins - the main factors responsible for the hemorrhagic symptoms following envenomation by snakes - have been purified from many snake venoms and characterized, presenting various molecular weights (MW). They can be divided into four classes based on their sizes and their domains contain, namely:

- Class I, the small toxins ranging from 20 to 30 $\mathrm{kDa}$ that have only the protease domain.

- Class II, the medium-size of 30 to $50 \mathrm{kDa}$ that have the protease and disintegrin-like domains.

- Class III, the most potent hemorrhagic toxins of 50 to $80 \mathrm{kDa}$ that have the protease, disintegrin-like and cysteine-rich domains.
- Class IV, toxins predicted only from cDNA sequences, present a MW of 80 to $100 \mathrm{kDa}$ and possess protease, disintegrin-like, cysteinerich and lectin-like domains (1).

Most molecules that provoke hemorrhage and damage to animal tissues are zincmetalloproteinases (2, 3). Agkistrodon acutus (five-paced snake) is native to southern China and its venom contains hemorrhagins, four of which have been purified and characterized: acutolysin $\mathrm{A}$, acutolysin B, acutolysin C and acutolysin D (4-6). Their isoelectric points (pI) are respectively 4.6, 5.3, 9.0 and 5.0. Acutolysin D is a protein of $44 \mathrm{kDa}$, while the other three present a MW of about $22 \mathrm{kDa}$. They exhibit different hemorrhagic activities (4). Acutolysin $\mathrm{C}$ is a basic glycoprotein 
of 203 amino acids long (AF17439.1) that has a minimum hemorrhagic dose (MHD) of 10.0 $\mu \mathrm{g}$ and weak lethal activity $(4,7)$. Preliminary $\mathrm{X}$-ray crystallographic analysis and the cDNA sequence (AF17439.1) were previously reported $(7,8)$. The hemorrhagin has two highly conserved characteristic sequences - His142Glu143-X-X- His146-X-X-Gly149-X-X-His152 and Cys162-Ile163-Met164 - and three disulfide bridges: Cys117-Cys195, Cys157-Cys179 and Cys159-Cys162. The entire structure shows good agreement with those of other reported class I hemorrhagins, having two subdomains with a cleft in which the catalytic zinc ion is localized. We now report the studies on enzyme activity, toxicity and agglutination activity of acutolysin $\mathrm{C}$, and the relationship between acutolysin $\mathrm{C}$ and C-type lectins is discussed.

\section{MATERIALS AND METHODS}

\section{Materials}

Lyophilized $A$. acutus venom was purchased from Yiwu Snake Research Institute, Yiwu city, Zhejiang Province, China. Plasmin, p-toluenesulfonyl arginine methyl ester (TAME), trypan blue, SDS, casein, polyacrylamide, bisacrylamide, protein weight marker and human fibrinogen were purchased from Sigma Chemical Co. (USA). All other reagents used were of analytical grade. Experimental animals were purchase from Zhejiang Academy of Medical Sciences. All animal experiments were conducted in accordance with the procedures of the Animal Research Ethics Committee, Zhejiang University.

\section{Purification}

Acutolysin $\mathrm{C}$ was purified according to the method of $\mathrm{Xu}$ et al. (4). One gram of crude lyophilized $A$. acutus venom was employed and acutolysin $C$ was purified by chromatography in DEAE-Sephadex A-50, CM-Sephadex C-50 and Sephadex G-75 in sequence.

\section{Homogeneity, Carbohydrate Assay and Atomic Absorption}

Acutolysin C homogeneity was determined by polyacrylaminde gel electrophoresis (PAGE), sodium dodecyl sulfate polyacrylamide gel electrophoresis (SDS-PAGE) and gradient SDS-PAGE. PAGE was carried out on $10 \%$ polyacrylamide gel by conventional methods using $0.03 \mathrm{M} \quad \beta$-alanine-acetic acid ( $\mathrm{pH}$ 4.5) running buffer. SDS-PAGE was carried out on $12 \%$ polyacrylamide gel in the presence and absence of the reducing agent, $\beta$-mercaptoethanol $(4 \%, v / v)$. The sample was boiled for ten minutes and submitted to electrophoresis. Gradient SDSPAGE was carried out on 5-20\% polyacrylamide gel by conventional methods. Molecular weight was determined by high-performance liquid chromatography-mass spectrometry (HPLCMS). Duplicate gels were run and one gel was stained with $0.1 \%$ Coomassie Brilliant Blue R-250 for proteins, and another was stained with periodic acid Schiff reagent for glycoproteins (9). Atomic absorption studies were carried out according to the method of Huang et al. (10).

\section{Enzyme Activity Assays}

Caseinolytic activity was assayed according to Kunitz (11). The reaction mixture containing 0.2 $\mathrm{mL}$ of acutolysin $\mathrm{C}$ solution $(1 \mathrm{mg} / \mathrm{mL})$ and 2.0 $\mathrm{mL}$ of casein solution $(1 \%, \mathrm{w} / \mathrm{v}, 0.1 \mathrm{M}$ Tris- $\mathrm{HCl}$, $\mathrm{pH}$ 7.6) was incubated at $37^{\circ} \mathrm{C}$ for 30 minutes. Then, $3.0 \mathrm{~mL}$ of trichloroacetic acid $(12.5 \% \mathrm{v} / \mathrm{v})$ was added and the mixture was incubated at $40^{\circ} \mathrm{C}$ for 15 minutes. After centrifuging at 4,500 $\mathrm{g}$ for 15 minutes, the absorbance of the supernatant was recorded at $280 \mathrm{~nm}$. One unit of caseinolytic activity was defined as the amount of enzyme which induced a 0.001 absorbance unit (AU) increase in absorbance per minute.

Inhibition of caseinolytic activity was assayed as follows: $0.1 \mathrm{~mL}$ acutolysin $\mathrm{C}$ solution (2 $\mathrm{mg} / \mathrm{mL}$ ) was mixed with $0.1 \mathrm{~mL}$ of a solution containing $500 \mathrm{mM}$ ethylene diamine tetra-acetic acid (EDTA) or $500 \mathrm{mM}$ ethylene glycol tetraacetic acid (EGTA) or $500 \mathrm{mM}$ cysteine or 500 $\mathrm{mM} 2$-mercaptoethanol or $500 \mathrm{mM}$ glutathione or $500 \mathrm{mM}$ 1,4-dithiothreitol or serum against acutolysin C (valence $=1: 1000$ ) or serum against homologous snake venom (valence $=1: 1000$ ) or $500 \mathrm{mM}$ glucose or $500 \mathrm{mM}$ sucrose or $500 \mathrm{mM}$ mannose or $500 \mathrm{mM}$ lactose or $500 \mathrm{mM}$ galactose. The mixture was incubated at $37^{\circ} \mathrm{C}$ for 30 minutes and then subjected to caseinolytic activity assay.

Fibrinolytic activity assays were measured with the fibrin-plate clearance method (12). Positive and negative controls were plasmin and $0.9 \% \mathrm{NaCl}$ respectively. The lysis diameters were measured against a dark background. Fibrinogenolytic activity was measured by the fibrinogen content at different time intervals, when incubated with 
acutolysin C. After incubation, the digestion was stopped by adding SDS-PAGE sample buffer and heating at $90^{\circ} \mathrm{C}$ for five minutes. The fibrinogen content was measured by the method of Rampling and Gaffney (13). Arginine esterase activity was assayed according to Huang et al. (14) using p-toluenesulfonyl arginine methyl ester (TAME) as the substrate. Phospholipase $\mathrm{A}_{2}$ activity was measured as suggested by Kawauchi and Iwanaga (15).

\section{Determination of Toxicity}

The hemorrhagic activity was assayed by the method of Kondo et al. (16), in which $0.1 \mathrm{~mL}$ of acutolysin $\mathrm{C}(0.5 \mathrm{mg} / \mathrm{mL})$ was injected into the depilated skin of the back of albino rabbits. In controls, $0.1 \mathrm{~mL}$ of normal physiological saline was used instead of the acutolysin $\mathrm{C}$ solution. Animals were humanely killed 24 hours after inoculation and the skins were removed. The minimum hemorrhagic dose (MHD) was defined as the amount of acutolysin $\mathrm{C}$ that produced a 10$\mathrm{mm}$ diameter hemorrhagic spot.

Cytotoxicity was determined as follows: mouse lymphocytes suspension was prepared and adjusted to $3.0 \times 10^{5}$ cells $/ \mathrm{mL}$. A mixture consisting of $4.5 \mathrm{~mL}$ of suspension and $0.5 \mathrm{~mL}$ of acutolysin C solution $(0.1 \mathrm{mg} / \mathrm{mL}$ in Hanks solution) was incubated at $37^{\circ} \mathrm{C}$. Then, $0.9 \mathrm{~mL}$ of the mixture was taken at 30 minute intervals and mixed with $0.1 \mathrm{~mL}$ of Trypan blue $(0.4 \% \mathrm{w} / \mathrm{w}$ in Hanks solution). The mixture was incubated at $37^{\circ} \mathrm{C}$ for ten minutes and afterward the number of dead cells, dyed by Trypan blue, was calculated. The lethal activity was determined by intraperitoneal (IP) injection into mice weighing 18 to $20 \mathrm{~g}$. The total volume used was $0.2 \mathrm{~mL}$. Five dose levels and six mice per dose level were used. The death rate was recorded after 24 hours and the $50 \%$ lethal dose $\left(\mathrm{LD}_{50}\right)$ was calculated according to Litchfield and Wilcoxon (17).

\section{Agglutination Assay}

Twenty-six of animals, including five species of mammals, six species of birds, three species of reptile and one species of amphibian, were employed for agglutination activity test. Animal lymphocytes suspension was prepared as follows: animals were killed and their spleens were taken out under sterile condition. The spleens were washed with Hanks solution and lymphocytes were squeezed-out gently with forceps in Hanks solution. The lymphocytes were washed with Hanks solution four times, centrifuged at 3,000 g for two minutes after washing. The suspension was adjusted to $5.8 \times 10^{7} / \mathrm{mL}$. Then, $0.1 \mathrm{~mL}$ acutolysin C solution $(0.1 \mathrm{mg} / \mathrm{mL}$ in Hanks solution) was added to $0.9 \mathrm{~mL}$ lymphocyte suspension and the mixture was incubated at $25^{\circ} \mathrm{C}$ for 30 minutes before being shaken gently. Lymphocyte clots formed where agglutination occurred.

Animal erythrocyte suspension was prepared as follows: whole blood was anticoagulated with sodium citrate $(3.8 \%, w / v, 1: 9)$, and centrifuged at $6,000 \mathrm{~g}$ for two minutes. Erythrocytes were washed with Hanks solution four times and adjusted to $5.8 \times 10^{7} / \mathrm{mL}$. The erythrocyte agglutination provoked by acutolysin C was determined by a similar method previously described. Platelet suspension was prepared mainly according to Mustard et al. (18). Whole blood was anticoagulated with sodium citrate $(3.8 \%, w / v, 1: 9)$, and centrifuged at $6,000 \mathrm{~g}$ for 15 minutes. The supernatant of platelet-rich plasma was centrifuged at $12,000 \mathrm{~g}$ for ten minutes. Platelets were washed with Tyrode's solution four times and adjusted to $4.2 \times 10^{8} / \mathrm{mL}$ in Tyrode's solution. Platelet agglutination was measured at $37^{\circ} \mathrm{C}$ with stirring (900 rpm). The extent of the platelet agglutination was continuously monitored for six minutes by turbidimetry and expressed as the increase in light transmission.

Inhibition of agglutination activity was determined as follows: $0.05 \mathrm{~mL}$ of acutolysin C solution $(0.2 \mathrm{mg} / \mathrm{mL}$ in Hanks solution) was mixed with $0.05 \mathrm{~mL}$ of the solution containing $500 \mathrm{mM}$ EDTA or $500 \mathrm{mM}$ EGTA or $500 \mathrm{mM}$ cysteine or $500 \mathrm{mM}$ 2-mercaptoethanol or 500 $\mathrm{mM}$ glutathione or $500 \mathrm{mM}$ 1,4-dithiothreitol or serum against acutolysin $\mathrm{C}$ (valence $=1: 1000$ ) or serum against homologous snake venom (valence $=1: 1000$ ) or $500 \mathrm{mM}$ glucose or $500 \mathrm{mM}$ sucrose or $500 \mathrm{mM}$ mannose or $500 \mathrm{mM}$ lactose or $500 \mathrm{mM}$ galactose. The mixture was incubated at $37^{\circ} \mathrm{C}$ for 30 minutes and then subjected to agglutination activity assay.

\section{RESULTS}

\section{Purification and Basic Properties}

Acutolysin $\mathrm{C}$ yield from $1 \mathrm{~g}$ crude $A$. acutus venom is shown in Table 1. Purification fold of acutolysin $\mathrm{C}$ was 11.2 times and yield was $21.2 \%$. The purified acutolysin $\mathrm{C}$ was homogenous as indicated 
Table 1. Acutolysin $C$ yield in purification procedure by chromatography (DEAE-Sephadex A-50, CMSephadex C-50 and Sephadex G-75)

\begin{tabular}{c|c|c|c}
\hline Steps & Total protein $(\mathbf{m g})$ & Recovery $(\%)$ & Purification fold \\
\hline Crude sample & 760.6 & 100 & 1.0 \\
\hline DEAE-Sephadex A-50 & 248.8 & 87.3 & 4.3 \\
\hline CM-Sephadex C-50 & 31.3 & 43.2 & 6.8 \\
\hline Sephadex G-75 & 14.1 & 21.2 & 11.2 \\
\hline
\end{tabular}

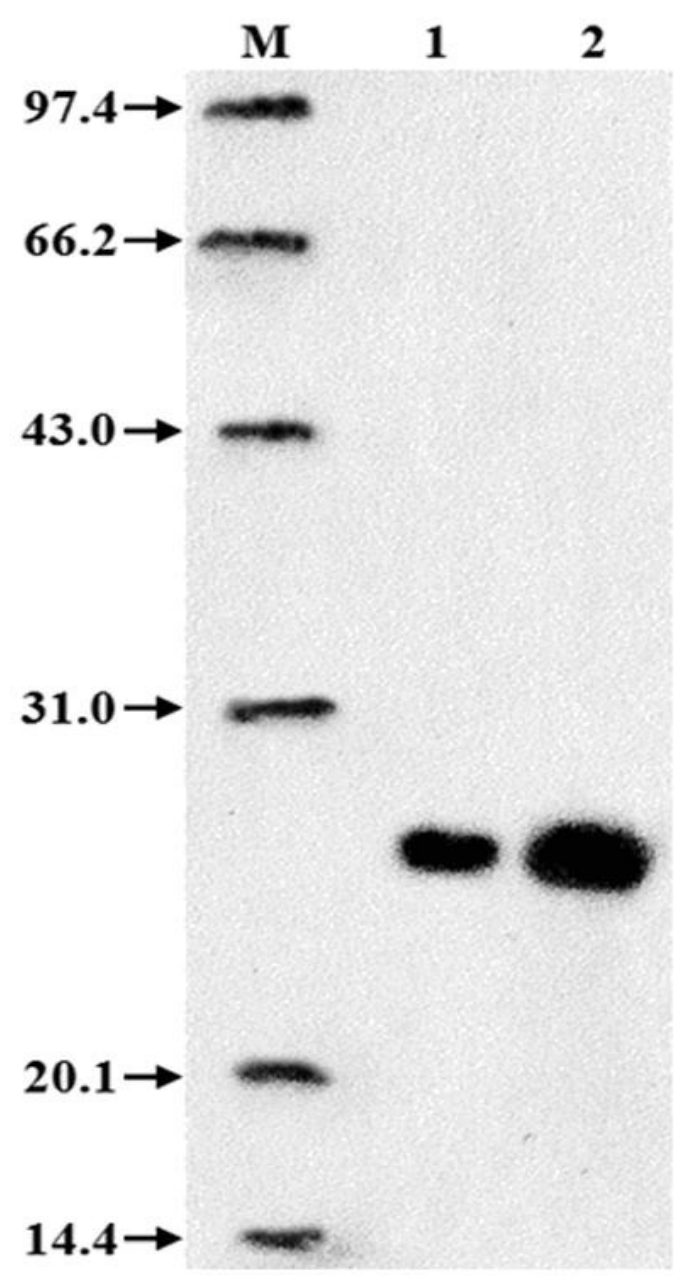

Figure 1. 12\% SDS-PAGE of acutolysin C from A. acutus venom. Lane 1: under non-reducing conditions; lane 2: under reducing conditions with $\beta$-mercaptoethanol; lane M: protein weight marker (rabbit phosphorylase b,97.4; bovine serum albumin, 66.2; rabbit action ovabumin, 43.0; bovine carbonic anhydrase, 31.0; trypsin inhibitor, 20.1; hen egg white lysozyme, 14.4). The positions of protein size markers $(\mathrm{kDa})$ are shown on the left.

by a single protein band on the $12 \%$ SDS-PAGE (Figure 1), PAGE at $\mathrm{pH} 4.5$, and in 5-20\% SDSPAGE. No difference was observed under reducing and non-reducing conditions. The results indicate that acutolysin $\mathrm{C}$ is a single polypeptide chain. The MW estimated by HPLC-MS is $23.1 \mathrm{kDa}$, which corresponds to the result of $12 \%$ SDS-PAGE analysis. Atomic absorption studies showed that it contains both $\mathrm{Zn}^{2+}$ and $\mathrm{Ca}^{2+}$ in the ratio of about 1:1.

\section{Enzyme Activity and Toxicity}

Acutolysin C demonstrated caseinolytic activity; however, it had no esterolytic, fibrinolytic, fibrinogenolytic or PLA 2 properties. It showed lethal activities with a $\mathrm{LD}_{50}$ of $7.6 \mathrm{mg} /$ $\mathrm{kg}$ for mice and weak hemorrhagic activity with MHD of $12.0 \mu \mathrm{g}$. It had no cytotoxicity below a concentration of $50 \mu \mathrm{g} / \mathrm{mL}$. Caseinolytic activity of acutolysin $\mathrm{C}$ was completely inhibited by EDTA, cysteine, 2-mercaptoethanol, 1,4-dithiothreitol or glutathione, and partly inhibited by EGTA, serum against acutolysin $\mathrm{C}$ and serum against homologous snake venom. Glucose, sucrose, mannose, lactose and galactose had no effects on its caseinolytic activity.

\section{Agglutination Activity}

Of the 26 species of tested animals, lymphocyte suspensions from all five mammals and all six birds were agglutinated, while those from all nine fish species were not. Among the reptiles, lymphocyte suspensions of Enhydris chinensis, Dinodon rufozonatum and Zaocys dhumnades were agglutinated, while those from Chinemys reevesii and Pelodiscus sinensis were not. Regarding amphibians, lymphocytes from Bufo gargarizans were agglutinated, while those from Rana catesbeiana Shaw were not (Table 2). The results of acutolysin C-induced agglutination of mouse lymphocytes are shown in Figure 2, and the lowest concentration to induce lymphocyte agglutination was $2.5 \mu \mathrm{g} / \mathrm{mL}$. Agglutination activity of acutolysin $\mathrm{C}$ in mouse lymphocytes was inhibited completely by EDTA, cysteine, 2-mercaptoethanol, 1,4-dithiothreitol and 
Table 2. Agglutination activities of acutolysin C in different animal lymphocytes, erythrocytes and platelets

\begin{tabular}{|c|c|c|c|c|}
\hline \multirow{2}{*}{ Animal class } & \multirow{2}{*}{$\begin{array}{l}\text { Animal species } \\
\text { (scientific name) }\end{array}$} & \multicolumn{3}{|c|}{ Agglutination activity } \\
\hline & & Lymphocytes & Platelets & Erythrocytes \\
\hline \multirow{9}{*}{ Pisces } & Monopterus albus & - & - & - \\
\hline & Ophiocephalus argus Cantor & - & - & - \\
\hline & Ctenopharyngodon idellus & - & - & - \\
\hline & Carassius auratus & - & - & - \\
\hline & Cyprinus carpio & - & - & - \\
\hline & Aristichthys nobilis & - & - & - \\
\hline & Clarias fuscus & - & - & - \\
\hline & Mylopharyngodon piceus & - & - & - \\
\hline & Pelteobagrus fulvidraco & - & - & - \\
\hline \multirow{2}{*}{ Amphibia } & Rana catesbeiana Shaw & - & - & - \\
\hline & Bufo gargarizans & + & - & - \\
\hline \multirow{5}{*}{ Reptilia } & Chinemys reevesii & - & - & - \\
\hline & Pelodiscus sinensis & - & - & - \\
\hline & Enhydris chinensis & + & - & - \\
\hline & Dinodon rufozonatum & + & - & - \\
\hline & Zaocys dhumnades & + & - & - \\
\hline \multirow{5}{*}{ Aves } & Anas platyrhynchos & + & - & - \\
\hline & Gallus gallus domosticus & + & - & - \\
\hline & Gallus gallus jabouillei & + & - & - \\
\hline & Phasianus colchicus & + & - & - \\
\hline & Anser cygnoides & + & - & - \\
\hline \multirow{5}{*}{ Mammalia } & Mus musculus & + & - & - \\
\hline & Oryctolagus cunieulus & + & - & - \\
\hline & Rattus norregicus & + & - & - \\
\hline & Erinaceus europaeus & + & - & - \\
\hline & Canis familiaris & + & - & - \\
\hline
\end{tabular}

+: positive, -: negative.

glutathione, and partly inhibited by serum against acutolysin $\mathrm{C}$ and serum against homologous snake venom. Glucose, sucrose, mannose, lactose, galactose and EGTA had no effects on its agglutination activity in mouse lymphocytes.

If mouse lymphocyte suspensions were treated with the inhibitors for 30 minutes at $37^{\circ} \mathrm{C}$ and then the inhibitors were washed out with Hanks solution, it was found that acutolysin C could agglutinate this lymphocyte suspension again. This suggests that the inhibition is mainly due to the interaction between inhibitor and acutolysin
C. Acutolysin $\mathrm{C}$ was stored at $-30^{\circ} \mathrm{C}$ in $\mathrm{PBS}$ for more than one year without significant loss of its agglutination activity, so that it maintained its activity after being frozen and thawed. The agglutination activity was lost after treatment for 16 minutes at $60^{\circ} \mathrm{C}, \mathrm{pH} 7.4$.

\section{DISCUSSION}

Most hemorrhagins are acidic or neutral proteins with strong hemorrhagic activity, and only a few are basic proteins. Acutolysin C was 


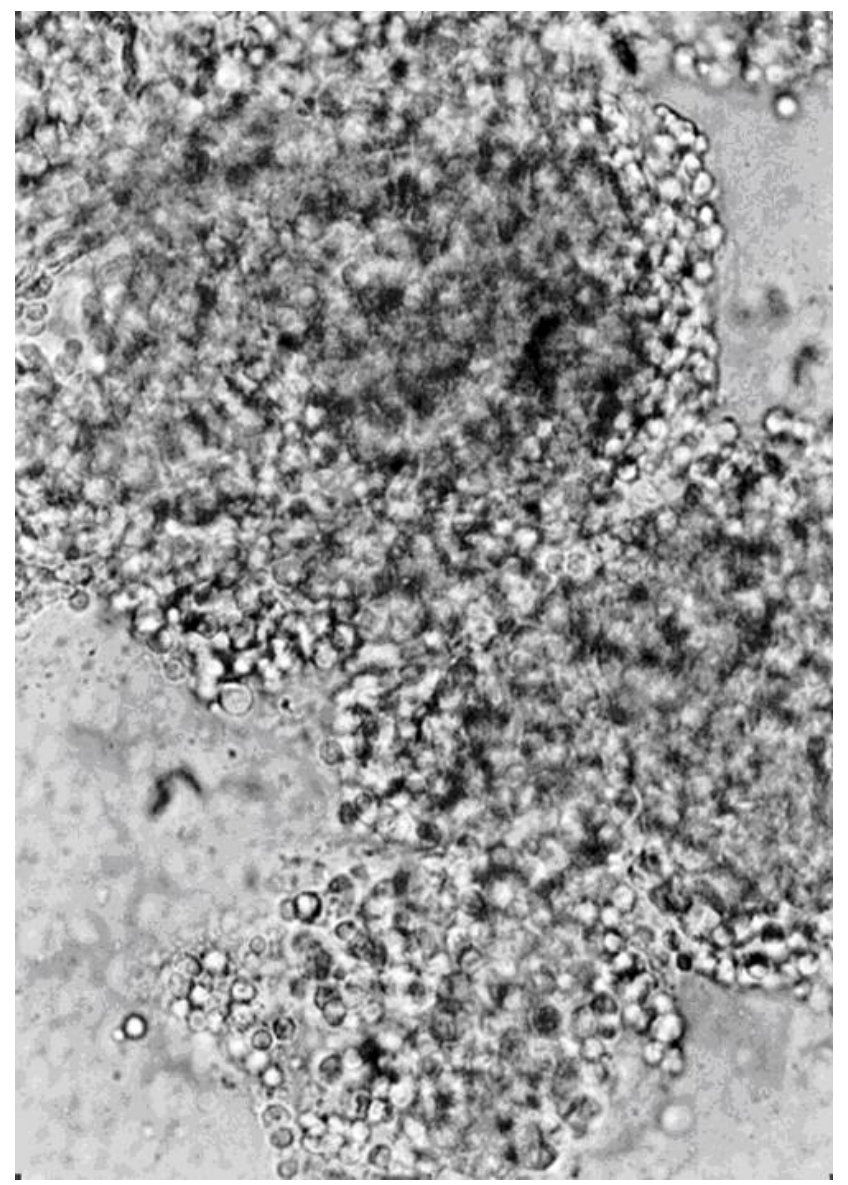

Figure 2. Photograph of agglutinated mouse lymphocytes induced by acutolysin C (40x). The reaction was conducted in Hanks solution with 10 $\mu \mathrm{g} / \mathrm{mL}$ of acutolysin C and $5.8 \times 10^{7}$ lymphocyte cells $/ \mathrm{mL}$ at $25^{\circ} \mathrm{C}$ for 30 minutes.

first isolated from $A$. acutus more than 20 years ago, but besides $\mathrm{LD}_{50}$ and $\mathrm{MHD}$, little is known about its properties. Our studies indicate that it is a basic glycoprotein consisting of a single polypeptide chain with a molecular weight of $23.1 \mathrm{kDa}$ and $\mathrm{pI}$ 8.7. It also possesses caseinolytic activity and has a weak lethal activity $\left(\mathrm{LD}_{50}=7.6\right.$ $\mathrm{mg} / \mathrm{kg}$ ) and weak hemorrhagic activity (MHD $=12.0 \mu \mathrm{g})$. The $\mathrm{LD}_{50}$ and MHD in this study were similar to the results of previous reports $\left(\mathrm{LD}_{50}=8.3 \mathrm{mg} / \mathrm{kg} ; \mathrm{MHD}=10.0 \mu \mathrm{g}\right)(4)$. Atomic absorption studies showed that it contains both $\mathrm{Zn}^{2+}$ and $\mathrm{Ca}^{2+}$. Its leucoagglutination activity and caseinolytic propoerties were completely inhibited by EDTA, which is due to the $\mathrm{Ca}^{2+}$ content. cDNA sequence analysis showed that acutolysin $\mathrm{C}$ has a zinc finger motif (7).

Preliminary X-ray crystallographic analysis showed that it has two subdomains with a cleft in which the catalytic zinc ion is localized (19). Predictions by Liu et al. (7) and Gong et al. (19) corroborate our present result about acutolysin C containing $\mathrm{Zn}^{2+}$.

Lectins are carbohydrate-binding proteins that are widely present in plants, animals and bacteria. C-type lectin is special type of lectin that requires $\mathrm{Ca}^{2+}$ for its activity. It is well known that snake venoms contain lectins, some of which exhibit saccharide-binding activity and induce agglutination of erythrocytes, several other target platelet membrane-proteins and/or blood coagulation factors, resulting in diverse biological effects. Gartner et al. (20) were the first to identify that the venom component responsible for hemaggregation was a lectin. Since then, several snake venom lectins have been isolated and characterized (21-29). Three types of lectin - agkisacutacin, ACFI and agkicetin - have been previously purified and identified from Agkistrodon acutus venom. Agkisacutacin exhibits anticoagulant activity and functions as a factor IX/factor X-binding protein, and is the first reported C-type lectin-like protein that binds to both platelet membrane receptors and coagulation factors $(30,31)$. ACFI is an anticoagulant C-type lectin-like protein that consists of two subunits and heterodimerization of these is required for its function (32). Agkicetin - obtained from the venom of the Taiwanese Agkistrodon acutus - is a disulfide-linked heterodimer that comprises subunits of 15 and $14 \mathrm{kDa}$ (33). It behaved as a potent antagonist of von Willebrand factorinduced platelet agglutination and bound specifically to GPIb of fixed platelets with high affinity.

Although leucoagglutination activity of acutolysin $\mathrm{C}$ is $\mathrm{Ca}^{2+}$-dependent and presents some properties of C-type lectins, such similarity is limited only to biological activity. There is no structural relationship between them. All the C-type lectins have one highly conserved characteristic sequence: CPS-X-WSSY-X-X-XCYK-X-F-X-X-X-X-X-WAD AE-X-FC-X-XQQ-X-X-X-X-HLVSFQS-X-EEADFVVK. This sequence is related to binding-carbohydrate groups on cell or platelet membranes and is called carbohydrate recognition domain (34). Acutolysin C does not contain C-type lectin special domain, but has two highly conserved characteristic sequences, including $\mathrm{His}_{142}{ }^{-}$ Glu $_{143}-\mathrm{X}-\mathrm{X}-\mathrm{His}_{146}-\mathrm{X}-\mathrm{X}-\mathrm{Gly}_{149}-\mathrm{X}-\mathrm{X}-\mathrm{His}_{152}$ and Cys $_{162}-$ Ile $_{163}-$ Met $_{164}-\mathrm{X}-\mathrm{X}-\mathrm{Gly}_{149}-\mathrm{X}-\mathrm{X}-\mathrm{His}_{152}$ and $\mathrm{Cys}_{162}-\mathrm{Ile}_{163}-\mathrm{Met}_{164}$ (7). This finding agrees with 
those of other reported class I hemorrhagins, including hemorrhagic metalloproteinase HR1a from Trimeresurus flavoviridis (AB074143.1, 80\%), VMP-III from Agkistrodon contortrix laticinctus (GQ451435.1, 82\%), acutolysin A from Agkistrodon acutus (AF174392.1, 80\%) and VMP-III from Agkistrodon piscivorus leucostoma (GQ451441.1, 79\%).

In our study, acutolysin C presented agglutination activity in lymphocytes from five species of mammals, six species of birds, three species of reptiles and one species of amphibian; but none in lymphocytes from two other species of reptiles, one of amphibian and nine of fish (Table 2). This suggests that leucoagglutination activity of acutolysin C in lymphocytes of "higher" animals is an evolutionary event. Acutolysin $\mathrm{C}$ had no effects on erythrocytes and platelets of the 26 animal species tested. Because its agglutination action requires $\mathrm{Ca}^{2+}$, acutolysin $\mathrm{C}$ possesses some properties of C-type lectins, but acts on different targets. This is the first report of a hemorrhagic toxin with lectin properties.

The leucoagglutination mechanism of acutolysin $\mathrm{C}$ is not clear. It is possible that acutolysin $\mathrm{C}$ contains two or more special binding sites that react with receptors or antigens on the lymphocyte membranes. Those receptors or antigens on lymphocyte membranes may only be found in "higher" animals, and not in fish. The leucoagglutination activity of acutolysin $\mathrm{C}$ would be a great help for animal evolution studies. Since its leucoagglutination activity is not inhibited by various types of sugar, it is not clear whether or not its binding sites contain a carbohydrate chain. Acutolysin $\mathrm{C}$ is interesting because it is the first member of the hemorrhagin family to be shown to have leucoagglutination activity.

\section{ACKNOWLEDGEMENTS}

We thank Dr. M. J. Adams, Rothamsted Research, Harpenden, UK, for help in correcting the English version of the manuscript, and Professor Xu Xun, Xiamen University, for her kind suggestions. This work was supported by the Natural Scientific Foundation of Anhui Province Education Commission and the S\&T Programme of Ningbo Sci-Tech Bureau.

\section{COPYRIGHT}

(C) CEVAP 2011

\section{SUBMISSION STATUS}

Received: July 21, 2010.

Accepted: October 25, 2010.

Abstract published online: November 5, 2010.

Full paper published online: February 28, 2011,

\section{CONFLICTS OF INTEREST}

There is no conflict.

\section{FINANCIAL SOURCE}

The Natural Scientific Foundation of the Anhui Province Education Commission (KJ2010A328) and the S\&T Programme of Ningbo Sci-Tech Bureau (2007C10081) provided the financial grants.

\section{ETHICS COMMITTEE APPROVAL}

The present study was approved by the Animal Research Ethics Committee, Zhejiang University.

\section{CORRESPONDENCE TO}

WEI CHUANBAO, Department of Chemistry and Biology, Western Anhui University, Lu'an City 237012, Anhui Province, People's Republic of China. Phone: +86564 3305073. Fax: +86 564 3305033. Email: weichuanbao@sina.com.

\section{REFERENCES}

1. Bjarnason JB, Fox JW. Snakevenom metalloproteinases: reprolysins. Meth Enzymol. 1995;248:345-68.

2. Kweon EYI, Lee DWI, Ahn MI, Nork TMII, Cho NCI. Vision loss following snakebite in a patient with controlled aplastic anemia. J Venom Anim Toxins incl Trop Dis. 2009;15(1):163-7.

3. Bjarnason JB, Fox JW. Haemorrhagic metalloproteinases from snake venoms. Pharmacol Ther. 1994;62(3):325-72.

4. Xu X, Wang C, Liu J, Lu Z. Purification and characterization of hemorrhagic components from Agkistrodon acutus (hundred pace snake) venom. Toxicon. 1981;19(5):633-44.

5. Zhu Z, Gong W, Niu L, Teng M, He H. Crystallization and preliminary X-ray diffraction study of hemorrhagin IV from snake venom of Agkistrodon acutus. Acta Cryst D. 1996; 52(2):407-8.

6. Zhu ZL, Gong WM, Zhu XY, Teng MK, Niu LW. Purification, characterization and conformational analysis of a haemorrhagin from the venom of Agkistrodon acutus. Toxicon. 1997; 35(2):283-92.

7. Liu QD, Xu WH, Cheng X, Liu J. Molecular cloning and sequence analysis of cDNA encoding acutolysin C, a hemorrhagic metalloproteinase, from Agkistrodon acutus. Acta Biochim Biophys Sin. 2000;32(4):425-29.

8. Gong WM, Zhu ZL, Niu LW, Teng MK. Preliminary $\mathrm{X}$-ray diffraction study on haemorrhagin AaHIII from 
snake venom of Agkistrodon acutus. Chinese Sci Bull. 1996;41(21):1824-6.

9. Glossmann H, Neville DM Jr. Glycoproteins of cell surfaces: comparative study of three different cell surfaces of the rat. J Biol Chem. 1971;246(20):633946.

10. Huang WZ, Wang C, Luo LQ, Lu ZX. Properties of NAD glycohydrolase purified from five-pace snake (Agkistrodon acutus) venom. Toxicon. 1988; 26(6):53542.

11. Kunitz M. Crystalline soybean trypin inhibitor II. General properties. J Gen Physiol. 1947;30(4):291310.

12. Bajwa SS, Markland FS, Russell FE. Fibrinolytic enzyme(s) in western diamondback rattlesnake (Crotalus atrox) venom. Toxicon. 1980;18(3):285-90.

13. Rampling MW, Gaffney PJ. The sulphite precipitation method for fibrinogen measurement; its use on small samples in the presence of fibrinogen degradation products. Clin Chim Acta. 1976;67(1):43-52.

14. Huang QQ, Teng MK, Niu LW. Purification and characterization of two fibrinogen-clotting enzymes from five-pace snake (Agkistrodon acutus) venom. Toxicon. 1999;37(7):999-1013.

15. Kawauchi S, Iwanaga S. Isolation and characterization of two phosphlipase A's from the Agkistrodon halys blomhoffi. Biochim Biophys Acta. 1971; 236(1):14260.

16. Kondo H, Kondo S, Ikezawa H, Murata R. Studies on the quantitative method for determination of hemorrhagic activity of Habu snake venom. Japan J Med Sci Biol. 1960;13:43-51.

17. Litchfield JR, Wilcoxon F. A simplified method of evaluating dose-effect experiments. J Pharmac Exp Ther. 1949;96(2):99-113.

18. Mustard JF, Perry DW, Ardlie NG, Packham MA. Preparation of suspensions of wash platelets from human. Br J Haematol. 1972;22(2):193-204.

19. Gong WM, Teng MK, Liu SJ, Niu, LW. Preliminary X-ray diffraction study on haemorrhagin AaH III from snake venom of Agkistrodon acutus. Chinese Sci Bull. 1997;42(22):2425-27.

20. Gartner TK, Stocker K, Williams DC. Thrombolectin: a lectin isolated from Bothrops atrox venom. FEBS Letts. 1980; 117(1):13-6.

21. Gartner TK, Ogilvie ML. Isolation and characterization of three $\mathrm{Ca}^{2+}$-dependent $\beta$-galactoside-specific lectins from snake venoms. Biochem J. 1984; 224(1):301-7.

22. Ogilvie ML, Dockter ME, Wenz L, Gartner TK. Isolation and characterization of lactose-binding lectins from the venoms of the snake Lachesis muta and Dendroaspis jamesonii. J Biochem(Tokyo). 1986;100(6):1425-31.

23. Ozeki Y, Matsui T, Hamako J, Suzuki M, Fujimura Y, Yoshida E, et al. C-type galactoside-binding lectin from Bothrops jararaca venom: comparison of its structure and function with those of Botrocetin. Arch Biochem Biophys. 1994; 308(1):306-10.

24. Aragón-Ortiz F, Mentele R, Auerswald EA. Amino acid sequence of a lectin-like protein from Lachesis muta stenophyrs venom. Toxicon. 1996; 34(7):763-9.

25. Komori Y, Nikai T, Tohkai T, Sugihara H. Primary structure and biological activity of snake venom lectin (APL) from Agkistrodon p. piscivorus (Eastern cottonmouth). Toxicon. 1999; 37(7):1053-64.

26. Nikai T, Kato S, Komori Y, Sugihara H. Amino acid sequence and biological properties of the lectin from the venom of Trimeresurus okinavensis (Himehabu). Toxicon. 2000; 38(5):707-11.

27. Jennings B, Spearman W, Shephard E. A novel $25 \mathrm{kDa}$ protein from the venom of Bitis arietans with similarity to C-type lectins causes fibrinogen-dependent platelet agglutination. Toxicon. 2005; 46(6):687-98.

28. Rádis-Baptista G, Moreno FBMB, Nogueira LL, Martins AMC, Toyama DO, Toyama MH, et al. Crotacetin, a novel snake venom C-type lectin, is homolog of convulxin. J Venom Anim Toxins incl Trop Dis. 2005;11(4):557-78.

29. Rádis-Baptista G. Integrins, cancer and snake toxins (mini-review). J Venom Anim Toxins incl Trop Dis. 2005;11(3):217-41.

30. Cheng X, Qian YW, Liu QD, Li BXY, Zhang MW, Liu J. Purification, characterization, and cDNA cloning of a new fibrinogenolytic venom protein, Agkisacutacin, from Agkistrodon acutus venom. Biochem Biophys Res Commun. 1999; 265(2):530-5.

31. Li WF, Chen L, Li XM, Liu J. A C-type lectin-like protein from Agkistrodon acutus venom binds to both platelet glycoprotein Ib and coagulation factor IX/factor X'. Biochem Biophys Res Commun. 2005;332(3):904-12.

32. $\mathrm{Hu} \mathrm{SY}, \mathrm{Li}$ WF, Chen L, Liu J. Expression of a recombinant anticoagulant C-type lectin-like protein ACFI in Pichia pastoris. Toxicon. 2005;46(7):716-24.

33. Chen YL, Tsai IH. Functional and sequence characterization of agkicetin, a new glycoprotein $\mathrm{Ib}$ antagonist isolated from Agkistrodon acutus venom. Biochem Biophys Res Commun. 1995; 210(2):472-7.

34. Zha XD, Zhang HY, Xiao YH, Liu J, Xu KS. Amplifying, cloning and expression of the cDNA encoding an unknown C-type lectin superfamily protein from Agkistrodon acutus. Prog Biochem Biophys. 2001;28(5):752-55. 